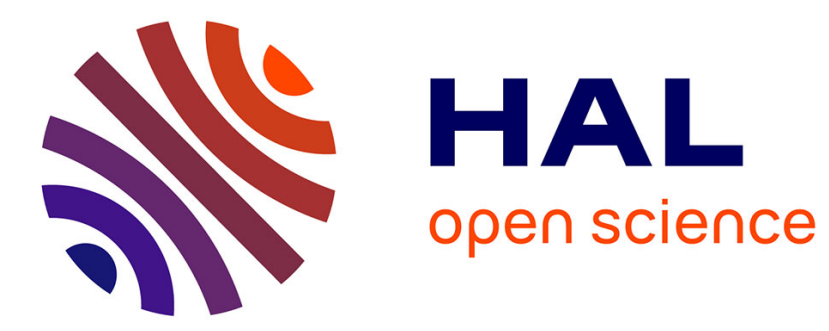

\title{
Dosage Thresholds and Influence of Transgene Cassette in Adeno-Associated Virus-Related Toxicity
}

Hanen Khabou, Chloé Cordeau, Laure Pacot, Sylvain Fisson, Deniz Dalkara

\section{To cite this version:}

Hanen Khabou, Chloé Cordeau, Laure Pacot, Sylvain Fisson, Deniz Dalkara. Dosage Thresholds and Influence of Transgene Cassette in Adeno-Associated Virus-Related Toxicity. Human Gene Therapy, 2018, 0, 10.1089/hum.2018.144 . hal-01927077

\section{HAL Id: hal-01927077 https://hal.sorbonne-universite.fr/hal-01927077}

Submitted on 19 Nov 2018

HAL is a multi-disciplinary open access archive for the deposit and dissemination of scientific research documents, whether they are published or not. The documents may come from teaching and research institutions in France or abroad, or from public or private research centers.
L'archive ouverte pluridisciplinaire HAL, est destinée au dépôt et à la diffusion de documents scientifiques de niveau recherche, publiés ou non, émanant des établissements d'enseignement et de recherche français ou étrangers, des laboratoires publics ou privés. 
Title:

Dosage thresholds and influence of transgene cassette in AAV-related toxicity

Authors:

Hanen Khabou ${ }^{1}$, Chloé Cordeau ${ }^{1}$, Laure Pacot $^{1}$, Sylvain Fisson ${ }^{2}$ and Deniz Dalkara $^{1}$

Affiliations :

${ }^{1}$ Sorbonne Universités, UPMC Univ Paris 06, INSERM, CNRS, Institut de la Vision, 17 rue Moreau, 75012 Paris, France.

²Généthon, Inserm UMR_S951, Univ Evry, Université Paris-Saclay, EPHE, Evry, France

Short title: AAV toxicity and consequences on data interpretation 


\section{Abstract}

Today, there are over 500 published studies and 40 clinical trials to treat retinal disorders using gene therapy. The great majority of them rely on the use of adenoassociated viral vectors (AAV) for therapeutic gene delivery and thus far AAVs have an excellent safety profile in the clinic. Nevertheless, it is known that AAV-mediated gene delivery leads to toxicity at high input doses in experimental gene therapy. Here we reveal the factors that contribute to retinal toxicity after subretinal administration of AAV vectors in wild-type mice. We show that alongside the input dose, the nature of the transgene and the cells mediating the expression determine the extent of toxicity. Importantly, we show that AAV vectors encoding GFP used as controls in experimental gene therapy are toxic at doses as low as $5 \times 10^{9} \mathrm{vg}$ confounding the observed therapeutic effect in gene therapy paradigms. Altogether our data show the importance of reducing input doses while increasing transgene expression levels via the use of more efficient capsids and promoters to avoid side effects in AAVmediated gene therapy. Furthermore, the toxicity observed with AAV-GFP vectors imply a re-interpretation of previous gene therapy studies where the therapeutic effect was measured in relation to this control. 


\section{Introduction}

Over the past twenty years, considerable efforts have been invested in establishing safe and effective gene therapy approaches for a multitude of diseases ${ }^{1}$. Applications in the retina have been particularly successful with positive outcomes and lack of side effects confirming the suitability of the eye as a target organ ${ }^{2}$. The use of adeno-associated viral (AAV) vectors has contributed to the success of retinal gene therapy in the clinic. AAVs ability to transduce a wide variety of tissues, and mediate long-term expression of the transgene after a single in vivo administration have made it the vector of choice. Indeed, wild-type AAV is not associated with any disease pathology in humans, and is also naturally replication-defective, requiring a helper virus such as adenovirus to replicate ${ }^{3}$. AAVs are one of the simplest gene delivery vectors, containing only the transgene expression cassette flanked by two non-coding viral inverted terminal repeats (ITRs) enclosed in a capsid composed of three structural proteins, VP1, 2, and $3^{4}$. The simplicity of AAV vectors, and their relatively low efficiency in transducing professional antigen presenting cells (APCs) (e.g. macrophages or dendritic cells) ${ }^{5-7}$ likely contribute to their generally low immunogenicity ${ }^{8}$. Moreover, transferred genomes tend to persist inside the cells primarily in an episomal, non-integrated form, reducing the chances of insertional mutagenesis ${ }^{9}$. All of these favorable properties are accountable for the success of AAV in gene therapy thus far.

The great majority of clinical trials thus far targeted the retinal pigment epithelium (RPE) cells, which are easily and efficiently transduced with vectors administered into the subretinal space. Indeed, RPE cells perform phagocytosis as one of their primary functions and their AAV mediated transduction is aided by the 
phagocytic properties of the RPE. Today, more translational studies are being undertaken targeting multiple retinal cell types and there is a noticeable increase in the number of clinical trials being prepared with diverse strategies from gene replacement ${ }^{10,11}$ to neuroprotection ${ }^{12}$ to optogenetics ${ }^{1,3}$ all of them using AAV as a vector. The nature of therapeutic proteins being expressed in these newer applications however demands higher-level gene expression, in more difficult-totransduce cell types than the RPE. These new studies are likely to put higher demands on AAV as a gene delivery vehicle and this will naturally lead to the use of higher input doses. In increasing AAV input doses, several potential obstacles need to be taken into account. These include but are not limited to; 1) phenotoxicity, i.e. problems arising from either overexpression or ectopic expression of the transgene; 2) immunotoxicity, i.e. harmful immune responses to either the capsid and/or to the transgene product ${ }^{14,15}$.

Thus far there have been a few studies reporting AAV gene delivery-related side effects in the retina ${ }^{16-19}$ but the vector components that are accountable for the toxicity have not been investigated individually. In this study we probed the interplay between the viral dose, the viral capsid, the encoded transgene, and the promoter driving transgene expression in mediating toxic effects. We have shown that the toxicity is directly correlated with the injected dose and can be entirely avoided at low doses. However, we have seen that AAV vectors encoding GFP are toxic to cells at doses as low as $5 \times 10^{9}$ particles per eye, a dose frequently used in experimental gene therapy studies ${ }^{20-30}$. We also showed that toxicity is dependent on the transgene as a retinal protein (retinoschisin) delivered through AAV at the same dose led to less toxicity than GFP. These findings indicate that AAV-GFP vectors regularly used as controls in gene therapy studies can be toxic, creating a bias for the eye 
treated with the therapeutic transgene urging a re-evaluation of some of the past studies $^{23,26,27,31}$. The GFP related phenotoxicity reported here should be taken into account in the design of future experimental gene therapies. As AAV capsid protein is responsible for most of the adverse effects even as non-coding capsids at high doses cause toxicity, the use of engineered AAVs with better infectivity and strong cell-type specific promoters should be favored over the use of higher doses with ubiquitous promoters. 


\section{Material and Methods}

\section{AAV production}

AAV vectors were produced as previously described using the co-transfection method and purified by iodixanol gradient ultracentrifugation ${ }^{34}$. AAV vector stocks were titered by quantitative $\mathrm{PCR}^{35}$ using SYBR Green (Thermo Fischer Scientific).

\section{Animals and intraocular injections}

The experiments were realized in accordance with the Nation Institutes of Health Guide for Care and Use of Laboratory Animals and approved by local ethics committees. Wild-type C57BL6/j mice (Janvier Labs) were used for this study. For ocular injections, mice were anesthetized by isofluorane inhalation. Pupils were dilated and a 33-gauge needle was inserted into the eye to deliver $1 \mu \mathrm{L}$ of AAV vector solution subretinally. Ophtalmic ointment (Fradexam) was applied after surgery. Eyes with extensive subretinal hemorrhage were excluded from the analysis. GFP expression was visualized using Micron III ophtalmoscope after dilation of the pupils and under isofluorane anesthesia.

\section{ERG recordings}

Mice were dark adapted overnight and then anesthetized. Pupils were dilated and mice were placed on a $37^{\circ} \mathrm{C}$ heated pad. Electrodes with contact lenses were positioned on the cornea of both eyes. A reference electrode was inserted into the forehead and a ground electrode into the back. ERGs were first recorded under scotopic conditions (Espion ERG System, Diagnosys) on a dark background. For recording of photopic ERGs, mice were initially exposed to a rod-saturating 
background for 10 minutes. Stimuli range was between 1,10 and $30 \mathrm{~cd} \times \mathrm{s} / \mathrm{m}^{2}$ and were presented 60 times (1 each second) on a rod-saturating background. Flicker ERGs were recorded following presentation of a $10-\mathrm{Hz}$ stimulus on a rod-saturating background. Data were analyzed with Espion ERG software, and then with GraphPad Prism.

\section{Histology, immunohistochemistry and microscopy}

Mouse eyes were enucleated and immediately fixed in 10\% formalin - $4 \%$ formaldehyde for 2 hours. After multiple washes and anterior parts removal, eyecups were immersed in PBS-30\% sucrose overnight at $4^{\circ} \mathrm{C}$. Afterwards they were embedded in OCT medium and frozen on frozen platforms immersed in liquid nitrogen. $10 \mu \mathrm{m}$-thick vertical sections were cut with a Microm cryostat. After incubation in a blocking buffer, sections were incubated with primary antibodies overnight at $4^{\circ} \mathrm{C}$ : Iba-1 antibody (019-19741, Wako); GFAP antibody (G3893, Sigma). After multiple washes of the sections, the secondary antibodies (Alexa Fluor 488 and 594, Thermo Fischer Scientific) were added for 2 hours at room temperature, followed by several washes. Retinal cryosections were mounted in Vectashield mounting medium (Vector Laboratories) for fluorescence microscopy and visualized using an Olympus confocal microscope. 


\section{Results}

\section{Toxicity thresholds for subretinally administered AAV8 vectors encoding GFP}

Subretinal injections have been the preferred administration route for gene delivery to photoreceptors and the retinal-pigmented epithelium (RPE). Input dose increase is often envisioned to increase therapeutic gene expression in gene therapy settings. To investigate the possible toxicity of vectors as a function of input dose, we used an AAV8 vector, frequently used for targeting the photoreceptors. The vector was produced at high titer and encoded GFP under a ubiquitous self complementary (sc)CAG promoter. We performed subretinal injections at a dose of $5 \times 10^{11} \mathrm{vg} / \mathrm{eye}$ in $1 \mu \mathrm{L}$ volume in $\mathrm{n}=5$ wild-type C57BL6/J mice, bilaterally. Reporter gene expression was monitored on a weekly basis with fluorescent eye fundus imaging. High level GFP expression was visible in all animals two weeks post dosing (Figure 1A). Interestingly, GFP expression decreased, starting at three weeks, as seen on the eye fundus images (Figure 1A,B). We next injected four lower AAV doses to find the dose at which toxicity starts. To this aim, $5 \times 10^{8}, 5 \times 10^{9}, 5 \times 10^{10}$, and $5 \times 10^{11}$ viral particles/eye were injected ( $n=8-10$ eyes per condition). Uninjected and PBS-injected animals served as controls ( $n=3-5$ eyes per condition). We measured the electroretinograms (ERGs) five weeks after injections. There was no significant effect of the PBS injection, showing that adverse effects are not due to surgical methods. However, we found a significant dose-related decrease in ERG amplitudes with doses equal to or above $5 \times 10^{9} \mathrm{vg}$ (Figure 1C). To determine whether retinal function alteration was attributable to cell loss we prepared retinal cryosections. We found a correlation between damage to the outer nuclear layer (ONL) and functional effects 
as a function of injected dose (Figure 1D). ONL loss was observed at $5 \times 10^{11}$ viral particles/eye.

A
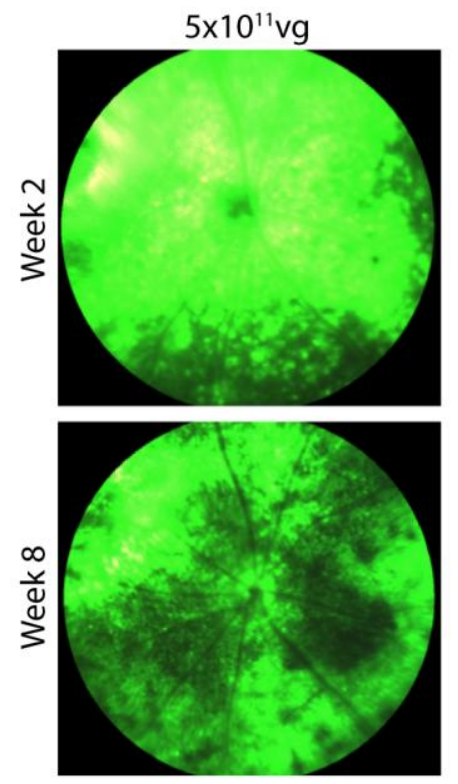

C

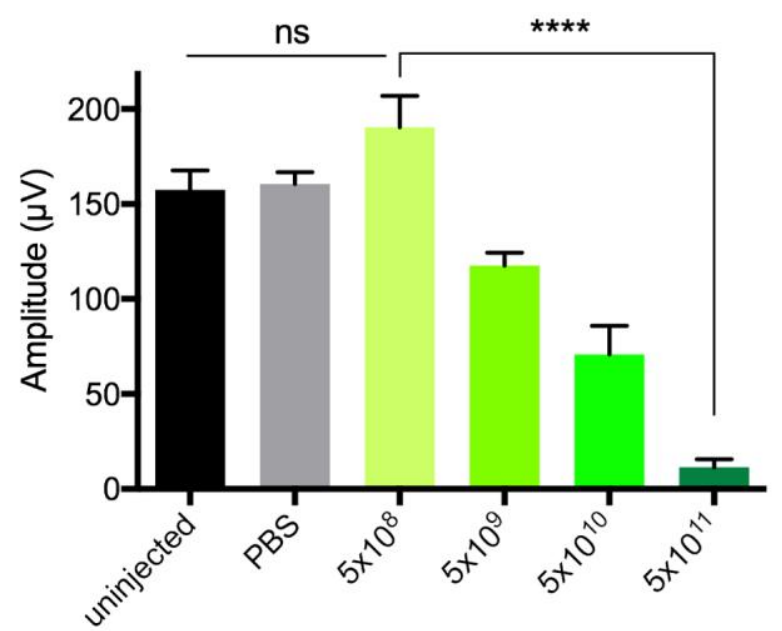

B

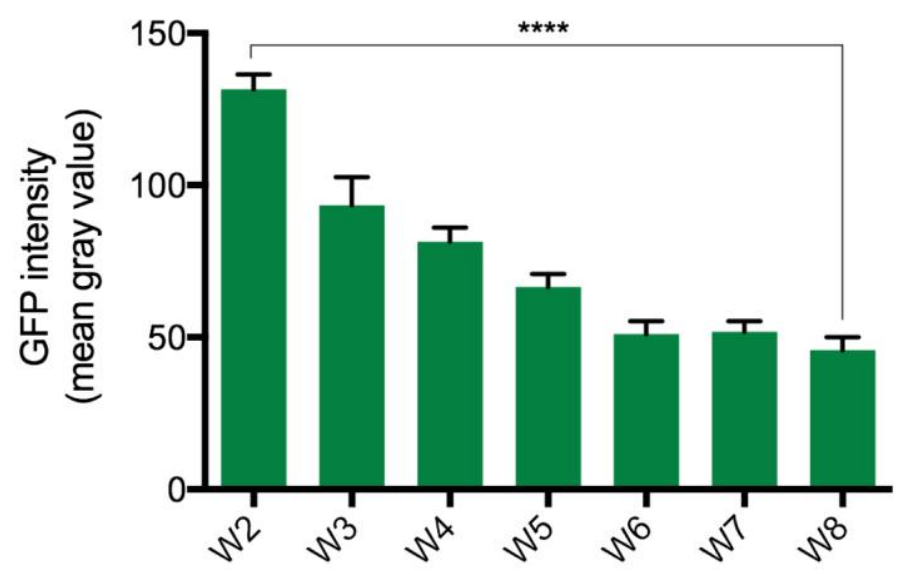

D
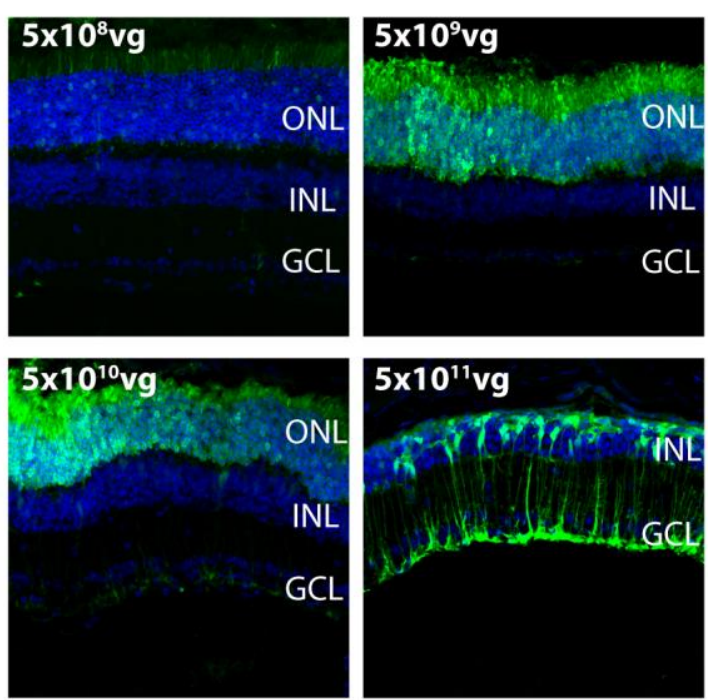

$5 \times 10^{11} \mathrm{vg}$

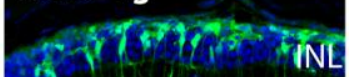

(2)

Figure 1: Effect of AAV8-scCAG-GFP injection on retinal structure and function. (A) Representative eye fundus images showing GFP fluorescence using $5 \times 10^{11} \mathrm{vg} / \mathrm{eye}$ at 2 and 8 weeks post-injection. (B) GFP expression as a function of time calculated as mean gray value in fluorescent fundus images across $n=10$ retinas. Erros bars are mean \pm SEM. Kruskal-Wallis test, $P$ value is expressed as the following: $P^{\star * * *}: P<0.0001$. (C) Photopic ERG b-wave amplitudes averaged across $n=8-10$ eyes per dose at 5 weeks post dosing. Erros bars show mean \pm SEM. Kruskal-Wallis test, $P$ value is expressed as the following: $P^{* * * *}: P<0.0001$; ns : non significant. (D) Representative cryosections of retinas injected with increasing AAV doses 8 weeks after injections. GFP is shown in green and DAPI staining for nuclei in blue. ONL : Outer Nuclear Layer ; INL : Inner Nuclear Layer ; GCL : Ganglion Cell Layer ; vg : viral genome. 


\section{AAV capsids and transgene overexpression together cause toxicity}

The toxicity occurring at high AAV input doses can be attributed to either the capsid and/or to the transgene product. To better understand the causes of the observed phenotoxicity, we performed equal dose unilateral injections with an AAV8 vector encoding GFP or the same vector where the transgene is oriented in reverse orientation in between loxP sites. This AAV (referred to as AAV8-flox) can only lead to expression in cells expressing Cre recombinase and therefore serves as noncoding control in our experiments. We observed about 30\% ERG amplitude decrease with AAV8-flox vector, suggesting that the capsid alone is responsible for a significant part of the toxicity. ERGs became un-recordable with an equal amount of AAV8-GFP, suggesting that the combination of high amounts of AAV capsid proteins and GFP is severely toxic to the retina.

Since GFP is a protein not normally found in the mammalian retina, we asked whether a retinal protein would also induce toxicity at high doses. To this aim, we injected a high dose $\left(1 \times 10^{11} \mathrm{vg}\right)$ of the same AAV vector encoding retinoschisin, a protein already expressed in the retina. We found there was about a $65 \% \mathrm{ERG}$ decrease with high dose AAV8 encoding retinoschisin (Figure 2A). This suggests that even proteins normally expressed in the retinal lead to toxicity when overexpressed or expressed in other cell types than those that usually produce the protein. Nevertheless, retinal proteins led to less severe toxicity compared to GFP as shown by recordable ERGs in retinas overexpressing retinoschisin.

Since the cell types expressing GFP can play a role, namely in immunotoxicity (i.e. harmful immune responses to GFP), we then asked whether a cell-type specific promoter could influence the toxicity. We compared expression of GFP under two 
strong promoters; the ubiquitous CAG promoter versus rod specific rhodopsin promoter. Interestingly, GFP expression under the rhodopsin promoter was stronger (Supplemental Figure 1) but GFP expressed under CAG promoter led to significantly more toxicity (Figure 2B).

A

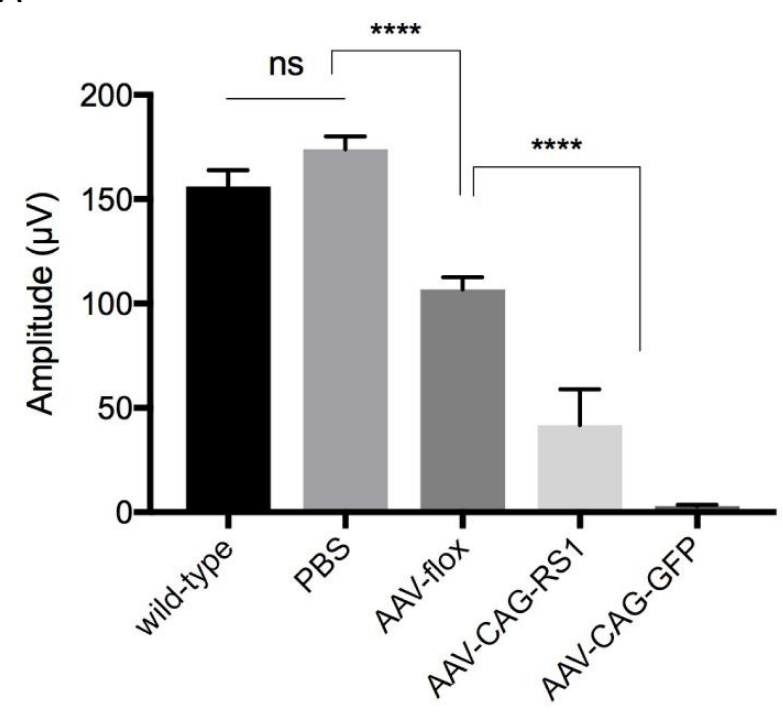

B

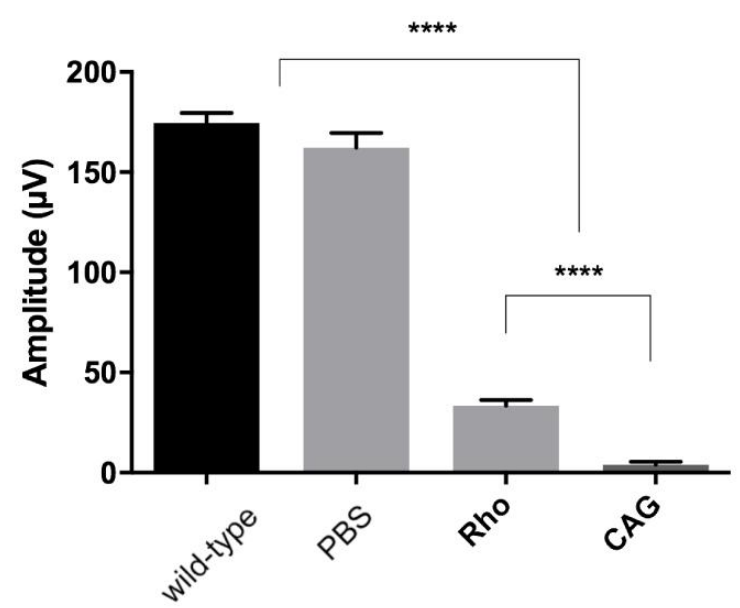

Figure 2: Functional retinal defects caused by high input AAV doses. (A) Effect of AAV capsid and transgene products amounts. Photopic ERG recordings (b wave) using AAV8-flox ( $n=13$ eyes) AAV8-CAGGFP ( $n=11$ eyes) or AAV8-CAG-RS1 ( $n=3$ eyes), using the highest doses, $1 \times 10^{11} \mathrm{vg} /$ eye subretinally. KruskalWallis test, $P$ value is expressed as the following: $P^{* * * *}: P<0.0001 ;$ ns : non-significant. (B) Effect of ubiquitous versus cell specific promoter on retinal function. Photopic ERG recordings using AAV8-CAG-GFP ( $n=10$ eyes) or AAV8-Rho-GFP ( $n=9$ eyes), with a dose of $5 \times 10^{11} \mathrm{vg} /$ eye subretinally. Kruskal-Wallis test, $P$ value is expressed as the following: $P^{\star \star * *}: P<0.0001$. All error bars are mean \pm SEM. Ni : non injected; RS1: retinoschisin; Rho : Rhodopsin promoter.

\section{Local immune responses to high input doses of AAV-GFP}

The toxicity observed in our experiments can be attributed to immunotoxicity, i.e. harmful immune responses to the capsid and the transgene product. Using AAV8-scCAG-GFP vector, GFP expression was found in RPE, photoreceptors and 
Müller glial cells involved in mediating immune reactions. We thus asked whether local immune responses were elicited within the retina. Two months after subretinal injections of AAV8-scCAG-GFP, we prepared retinal cryosections and found positive immunostainings for GFAP, a marker for Müller glial cell activation, and Iba-1, a marker for microglial cell activation. No labeling was observed with either marker in PBS-treated retinas (Figure 3).

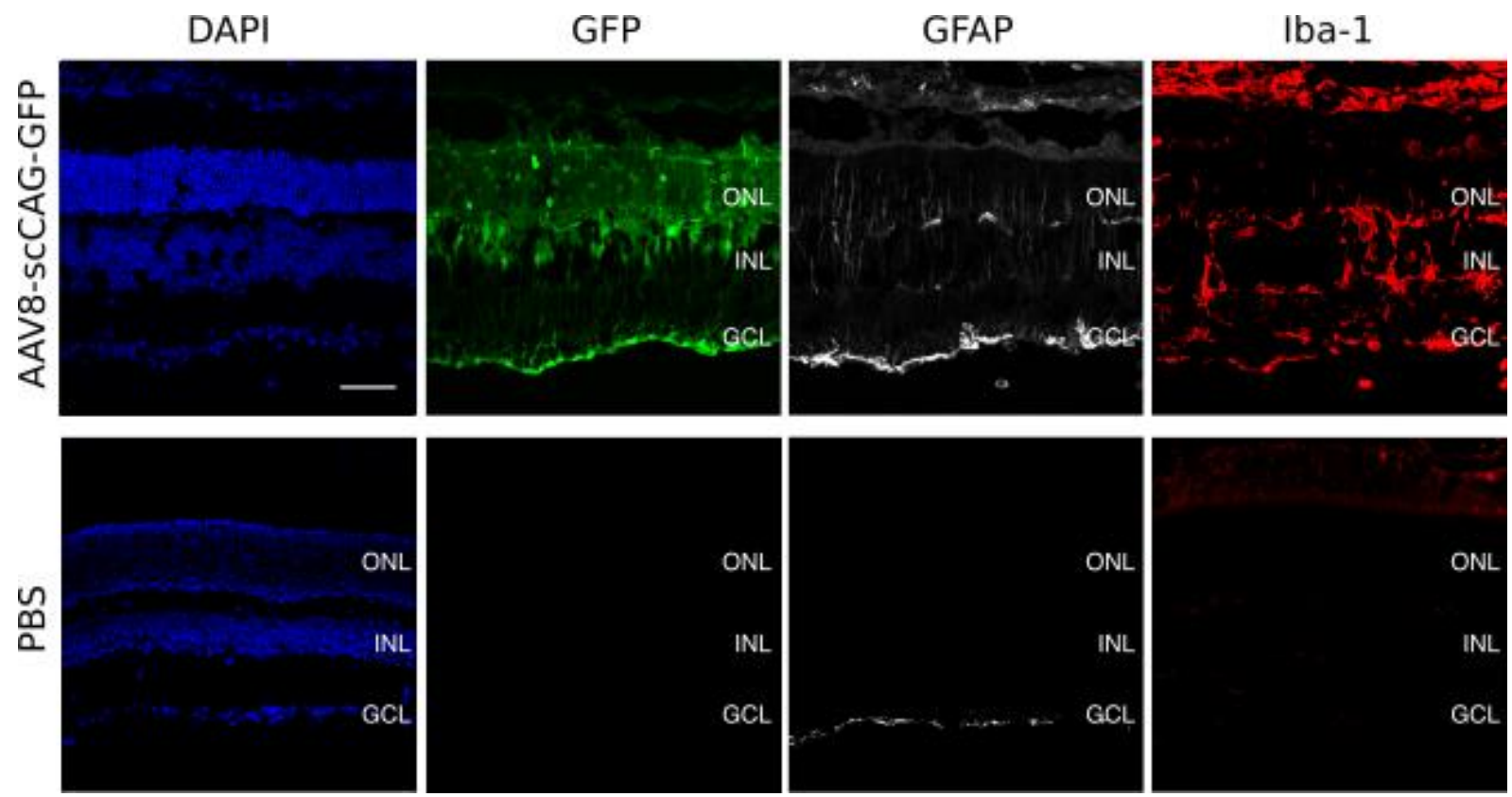

Figure 3 : Local immune reactions to high dose AAV-GFP. Representative retinal cryosections showing GFAP and Iba1 immunostainings after subretinal injection of (A) $5 \times 10^{11} \mathrm{vg}$ of AAV8-GFP or (B) PBS. ONL : Outer

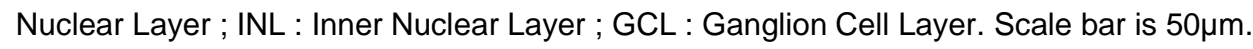




\section{Discussion}

Gene therapy holds promise for treating patients with inherited diseases. It is generally admitted that AAVs have an excellent safety profile, are non toxic and display low immunogenicity, nevertheless pre-clinical and clinical experience showed that AAV components can be recognized by the host immune system ${ }^{32}$. The extent of the impact of potential toxicity or inflammation on therapeutic efficiency remains poorly understood. In this context it is important to investigate what aspects of AAV vectors can induce toxic effects, in order to control them in gene therapy protocols. Indeed, there are now a few reports supporting acute toxicity from AAV at high-input doses, such as injections in the brain ${ }^{33,34}$ or systemic injections to treat liver disorders ${ }^{35}$, but also when transducing embryonic stem cells in vitro, likely through disruption of DNA damage pathways ${ }^{36}$. Mechanism of AAV induced toxicity is likely distinct for each scenario.

We showed here that $A A V$ is toxic to the retina, at high input doses. High doses of AAV capsids without any transgene expression, lead to retinal toxicity suggesting that the AAV capsid by itself accounts for part of the toxicity. Vectors encoding GFP were significantly more toxic, suggesting both the capsid and the transgene play a role in toxicity. Based on this data, GFP encoding vectors should be carefully dosed when used as controls in gene therapy experiments as high-level GFP expression in control retinas can give rise to a false therapeutic effect by increasing the difference between control and treated groups. The nature of the transgene also plays a role in toxicity, as a mammalian retinal protein led to less severe toxicity than foreign GFP. Interestingly, there was no direct correlation between the amount of GFP expression and the extent of toxicity as restricting GFP 
expression to rods diminished toxic effects despite providing higher expression levels. This suggests there is not only phenotoxicity due to overexpression but that ectopic expression plays an important role. There are reports suggesting that the immune system plays a role in the toxic side effects observed at higher doses ${ }^{19}$ with cellular responses mediating clearance of the transduced cells ${ }^{32}$.

One limitation of our study is the use of mice, as non-human primates are better models to assess immunogenicity and toxicity towards AAV. But even in this rodent model that is presumed to tolerate intraocular AAV injections, we found dose dependent structural and functional retinal defects, suggesting that more severe reactions can occur in primates ${ }^{16,19}$. Nevertheless, this study adds to our understanding of which AAV-related components correlate with side effects and inform us on the dosage thresholds to respect and factors to take into account to avoid toxicity in AAV mediated gene therapy.

Several studies suggest dosing thresholds to maintain safety ${ }^{16,19}$. However since there are numerous parameters that play a role on the efficacy of transduction and transgene expression -such as the promoter, the capsid and other cis regulatory elements- it is difficult to define one single dose for all retinal gene therapy settings. The threshold dose needs to be determined for each vector and target tissue, as a function of the administration route and animal model used. It has been shown in NHP studies, that intravitreal injections of $1 \times 10^{12} \mathrm{vg} / \mathrm{eye}$ or more is harmful and inflammatory when associated to GFP and ubiquitous promoters ${ }^{17,18}$. Subretinally the threshold seems to be lower and around to $1 \times 10^{11} \mathrm{vg} /$ eye in $\mathrm{NHPs}^{10,16,17}$ as higher doses were associated to inflammation ${ }^{19}$, also in patients ${ }^{37}$, likely because the vector is directly in contact with target cells. In mice the dose range is usually between $1 \times 10^{8}$ and $1 \times 10^{10} \mathrm{vg}^{10,38,39}$ 
Dose sparing using enhanced $A A V s$ that allow to use low particle numbers while maintaining satisfying expression levels is an attractive strategy to alleviate AAV related toxicity issues ${ }^{13}$. Engineered capsids can be combined with cell-type-specific promoters that restrict transgene expression to target cells further refining the safety and efficacy of gene therapy ${ }^{13,40}$. 


\section{Acknowledgments}

This study was supported by Marie Curie CIG (334130, RETINAL GENE THERAPY),

INSERM, Labex-Lifesenses (ANR-10-LABX-65), the Agence Nationale pour la Recherche - Recherche Hospitalo-Universitaire en santé (RHU) (Light4Deaf), Fondation NRJ. HK was supported by a PhD fellowship from the AFM-Téléthon. We thank Céline Winckler and Camille Robert for assistance with the production of plasmids and AAV vectors. 


\section{Author Disclosure Statement}

The authors report the following potential conflict of interest: H.K. and D.D are inventors on two pending patent application on non-invasive methods to target cone photoreceptors using novel adeno-associated viral variants. DD is an inventor on a patent on adeno-associated virus virions with variant capsid and methods of use thereof with royalties paid to Avalanche Biotech. D.D. is a consultant for GenSight Biologics. C.C., L.P. and S.F. report no conflict of interest. 


\section{References}

1. Dunbar CE, High KA, Joung JK, et al. Gene therapy comes of age. Science (80- ) 2018;359:eaan4672.

2. Bennett J. Taking Stock of Retinal Gene Therapy: Looking Back and Moving Forward. Mol Ther 2017;25:1076-1094.

3. Mouw MB, Pintel DJ. Adeno-associated virus RNAs appear in a temporal order and their splicing is stimulated during coinfection with adenovirus. J Virol 2000;74:9878-88.

4. Samulski RJ, Berns KI, Tan M, et al. Cloning of adeno-associated virus into pBR322: rescue of intact virus from the recombinant plasmid in human cells. Proc Natl Acad Sci U S A 1982;79:2077-81.

5. Jooss $\mathrm{K}$, Yang $\mathrm{Y}$, Fisher KJ, et al. Transduction of dendritic cells by DNA viral vectors directs the immune response to transgene products in muscle fibers. $\mathrm{J}$ Virol 1998;72:4212-23.

6. Zaiss A-K, Son S, Chang L-J. RNA 3' readthrough of oncoretrovirus and lentivirus: implications for vector safety and efficacy. J Virol 2002;76:7209-19.

7. VANDENDRIESSCHE T, THORREZ L, ACOSTA-SANCHEZ A, et al. Efficacy and safety of adeno-associated viral vectors based on serotype 8 and 9 vs. lentiviral vectors for hemophilia B gene therapy. J Thromb Haemost 2007;5:16-24.

8. Bennett J. Immune response following intraocular delivery of recombinant viral vectors. Gene Ther 2003;10:977-982.

9. Duan D, Sharma P, Yang J, et al. Circular intermediates of recombinant adenoassociated virus have defined structural characteristics responsible for longterm episomal persistence in muscle tissue. J Virol 1998;72:8568-77. 
10. Ye G, Budzynski E, Sonnentag P, et al. Cone-Specific Promoters for Gene Therapy of Achromatopsia and Other Retinal Diseases. Hum Gene Ther 2016;27:72-82.

11. Scalabrino ML, Boye SL, Fransen $\mathrm{KMH}$, et al. Intravitreal delivery of a novel AAV vector targets ON bipolar cells and restores visual function in a mouse model of complete Congenital Stationary Night Blindness. Hum Mol Genet 2015;9342:1-32.

12. Byrne LC, Dalkara D, Luna G, et al. Viral-mediated RdCVF and RdCVFL expression protects cone and rod photoreceptors in retinal degeneration. J Clin Invest 2015;125:105-116.

13. Khabou H, Garita-Hernandez M, Chaffiol A, et al. Noninvasive gene delivery to foveal cones for vision restoration. JCI Insight 2018;3:e96029.

14. Manno CS, Pierce GF, Arruda VR, et al. Successful transduction of liver in hemophilia by AAV-Factor IX and limitations imposed by the host immune response. Nat Med 2006;12:342-7.

15. Mingozzi F, Maus M V, Hui DJ, et al. CD8+ T-cell responses to adenoassociated virus capsid in humans. Nat Med 2007;13:419-422.

16. Vandenberghe $\mathrm{LH}$, Bell $\mathrm{P}$, Maguire AM, et al. Dosage Thresholds for AAV2 and AAV8 Photoreceptor Gene Therapy in Monkey. Sci Transl Med $2011 ; 3: 88$ ra54.

17. Ramachandran P, Lee V, Wei Z, et al. Evaluation of dose and safety of AAV7m8 and AAV8BP2 in the non-human primate retina. Hum Gene Ther $2016 ; 1-40$.

18. Dalkara D, Byrne LLC, Klimczak RR, et al. In vivo-directed evolution of a new adeno-associated virus for therapeutic outer retinal gene delivery from the 
vitreous. Sci TransI Med 2013;5:189ra76.

19. Reichel FF, Dauletbekov DL, Klein R, et al. AAV8 Can Induce Innate and Adaptive Immune Response in the Primate Eye. Mol Ther 2017;25:1-13.

20. Liang FQ, Aleman TS, Dejneka NS, et al. Long-term protection of retinal structure but not function using rAAV.CNTF in animal models of retinitis pigmentosa. Mol Ther 2001;4:461-472.

21. Ho TT, Maguire AM, Aguirre GD, et al. Phenotypic rescue after adenoassociated virus-mediated delivery of 4-sulfatase to the retinal pigment epithelium of feline mucopolysaccharidosis VI. J Gene Med 2002;4:613-21.

22. Adamus G, Sugden B, Shiraga S, et al. Anti-apoptotic effects of CNTF gene transfer on photoreceptor degeneration in experimental antibody-induced retinopathy. J Autoimmun 2003;21:121-9.

23. Narfström K, Katz ML, Bragadottir R, et al. Functional and structural recovery of the retina after gene therapy in the RPE65 null mutation dog. Invest Ophthalmol Vis Sci 2003;44:1663-72.

24. Yokoi K, Zhang HS, Kachi S, et al. Gene Transfer of An Engineered Zinc Finger Protein Enhances the Anti-angiogenic Defense System. Mol Ther 2007;15:1917-1923.

25. Leonard KC, Petrin D, Coupland SG, et al. XIAP Protection of Photoreceptors in Animal Models of Retinitis Pigmentosa. PLoS One 2007;2:e314.

26. Gorbatyuk M, Justilien V, Liu J, et al. Preservation of photoreceptor morphology and function in $\mathrm{P} 23 \mathrm{H}$ rats using an allele independent ribozyme. Exp Eye Res 2007;84:44-52.

27. Seo S, Krebs MP, Mao H, et al. Pathological consequences of long-term mitochondrial oxidative stress in the mouse retinal pigment epithelium. Exp Eye 
Res 2012;101:60-71.

28. Wassmer SJ, Leonard BC, Coupland SG, et al. Overexpression of the XLinked Inhibitor of Apoptosis Protects Against Retinal Degeneration in a Feline Model of Retinal Detachment. Hum Gene Ther 2017;28:482-492.

29. Mao H, James $T$, Schwein A, et al. AAV delivery of wild-type rhodopsin preserves retinal function in a mouse model of autosomal dominant retinitis pigmentosa. Hum Gene Ther 2011;22:567-75.

30. Mao H, Gorbatyuk MS, Rossmiller B, et al. Long-term rescue of retinal structure and function by rhodopsin RNA replacement with a single adenoassociated viral vector in $\mathrm{P} 23 \mathrm{H}$ RHO transgenic mice. Hum Gene Ther 2012;23:356-66.

31. Yokoi K, Kachi S, Zhang HS, et al. Ocular gene transfer with selfcomplementary AAV vectors. Invest Ophthalmol Vis Sci 2007;48:3324-8.

32. Mingozzi F, High KA. Overcoming the Host Immune Response to AdenoAssociated Virus Gene Delivery Vectors: The Race Between Clearance, Tolerance, Neutralization, and Escape. Annu Rev Virol 2017;4:511-534.

33. Klein RL, Dayton RD, Leidenheimer NJ, et al. Efficient Neuronal Gene Transfer with AAV8 Leads to Neurotoxic Levels of Tau or Green Fluorescent Proteins. Mol Ther 2006;13:517-527.

34. Cearley $\mathrm{CN}$, Wolfe $\mathrm{JH}$. Transduction characteristics of adeno-associated virus vectors expressing cap serotypes $7,8,9$, and Rh10 in the mouse brain. Mol Ther 2006;13:528-37.

35. Hinderer C, Katz N, Buza EL, et al. Severe toxicity in nonhuman primates and piglets following high-dose intravenous administration of an AAV vector expressing human SMN. Hum Gene Ther 2018;in press. 
36. Hirsch ML, Fagan BM, Dumitru R, et al. Viral Single-Strand DNA Induces p53Dependent Apoptosis in Human Embryonic Stem Cells. PLoS One 2011;6:113.

37. Bainbridge JWB, Mehat MS, Sundaram V, et al. Long-Term Effect of Gene Therapy on Leber's Congenital Amaurosis. N Engl J Med 2015;372:18871897.

38. Allocca M, Mussolino C, Garcia-Hoyos M, et al. Novel adeno-associated virus serotypes efficiently transduce murine photoreceptors. J Virol 2007;81:1137211380.

39. Allocca M, Manfredi A, lodice C, et al. AAV-Mediated Gene Replacement, Either Alone or in Combination with Physical and Pharmacological Agents , Results in Partial and Transient Protection from Photoreceptor Degeneration Associated with nL PDE Deficiency. IOVS;52 . Epub ahead of print 2011. DOI: 10.1167/iovs.10-6269.

40. Chaffiol A, Caplette R, Jaillard C, et al. A New Promoter Allows Optogenetic Vision Restoration with Enhanced Sensitivity in Macaque Retina. Mol Ther 2017;25:2546-2560. 